\title{
EL LENGUAJE Y LA ESTRUCTURACIÓN PRÁCTICA DE LA EXISTENCIA
}

\section{LANGUAGE AND PRACTICAL ESTRUCTURATION \\ OF EXISTENCE}

SAMUEL M. CABANCHIK

UBA/UNL/CONICET, Argentina

\begin{abstract}
RESUMEN: En el presente trabajo me propongo explorar diversos aspectos implicados en la concepción práctica del lenguaje. Desde el punto de vista metodológico, se argumentará en favor de la pertinencia de las consideraciones ontogenéticas y filogenéticas, desde la perspectiva del hablante/intérprete, para el tratamiento de los problemas semánticos y semióticos del lenguaje. Descripto este contexto, se hará foco en la estructura actancial que atraviesa el lenguaje, mostrando su irreductibilidad para una representación teórica del mismo. Desde el punto de vista práctico así concebido, se expondrán imágenes del lenguaje en la mayoría de las cuales, más allá de sus profundas diferencias, parece imponerse un elemento mítico que fungiría como sustituto de la imposibilidad de fundamento teórico. Así, se compararán las estampas producidas en las obras de Bajtín, Benjamin, Rosenzweig, Sartre y Wittgenstein, valorando el componente mítico y el componente crítico en sus respectivas concepciones del lenguaje. La pregunta que guiará este trabajo comparativo, es el papel que cabe asignarle a la polarización conciencia-comunidad en la constitución práctica del lenguaje, y las diferentes maneras en que las estructuras materiales y objetivas se integran en ella. A partir de este punto pivote, se establecerá una gradación entre las imágenes referidas, según la cual iremos del extremo mítico de un Benjamin al extremo crítico de un Bajtín. Finalmente, más allá de esta gradación, se intentará responder si es posible una concepción práctica del lenguaje puramente crítica, esto es, más allá de todo mito.
\end{abstract}


Palabras clave: Filosofía del lenguaje, Bajtín, Benjamin, Rosenzweig, Sartre, Wittgenstein.

Авstract: In this paper, I intend to explore various aspects involved in the practical conception of language. From a methodological point of view, we will argue in favor of the relevance of ontogenetic and phylogenetic considerations; from the perspective of the speaker / performer, we will study the treatment of semantic and semiotic problems of language. Having described this context, we shall focus on the actantial structure that is transversal to language, showing it to be non-reducible for a theoretical representation of language. Conceived in this way, from a practical point of view, images of language will be presented, most of which, beyond their profound differences, seem to impose themselves upon a mythical element that would function as a substitute of the impossibility of any theoretical foundation. Thus, the impressions produced in the works of Bakhtin, Benjamin, Rosenzweig, Sartre, and Wittgenstein are compared, valuing the mythical component and the critical component in their conceptions of language. The question that will guide this comparative work is the role that can be assigned to the consciousness-community polarization in the practical constitution of language, and the difference ways in which the material and objectives structures are integrated in it. Starting with this pivotal point, a gradation among the images mentioned will be established, according to which we shall go from the mythical extreme of Benjamin to the critical extreme of Bakhtin. Finally, beyond this gradation, we shall try to respond to the question of whether a practical conception of purely critical language is possible, that is, beyond all myth.

KeYwords: Philosophy of language, Bakhtin, Benjamin, Rosenzweig, Sartre, Wittgenstein.

A través de su historia, la filosofía se manifiesta cifrando su autoconciencia en diversas configuraciones esenciales. Se impone con evidencia irrefutable que lo propio de la contemporaneidad filosófica ha encontrado en el lenguaje su pivote o configuración esencial. (Con mayor audacia, podría pretenderse que esa dimensión axial es connatural a la filosofía como tal, y que de hecho así se ha manifestado en su origen en las más diversas tradiciones, de oriente a occidente).

Los afanes más profundos de la filosofía buscaron en la esencia del lenguaje la comunicabilidad de lo originario, entendido como lo absoluto. Absoluto significa a la vez libre y absuelto, de modo que, si el lenguaje es lo absoluto, ha de tratarse de la concreción misma de lo espiritual, esto es, de una potencia inagotable e irreductible, o, como también cabe especificar, infinita. 
La consecuencia inevitable de este reconocimiento, es que el lenguaje permanece más allá del concepto, porque todo concepto lo traiciona, al menos parcialmente. Es una situación desesperada para la filosofía, pues también el concepto le es connatural, con lo que debe servir a dos dioses cuya tensa convivencia es el precio de su hipoteca no cancelable: lo que vuelve posible a la filosofía, es lo que la lleva a fracasar en su aspiración máxima, la de dar caza al absoluto diciéndolo.

Anoticiados de ese límite infranqueable, somos confinados a ubicar al lenguaje en la base de todas las mediaciones a través de las cuales esa Unidad o Totalidad, amenazada con devenir mítica, se diferencia y articula. Se abre así el abanico de todas las dicotomías - o n-cotomías, si se me permite el neologismo - con las que el pensamiento filosófico se organiza, tanto en la formulación de sus problemas como en la sistematicidad de sus soluciones.

Heráclito, Parménides o todas sus mezclas dan igual, pues "el logos quiere y no quiere ser llamado con el nombre de Zeus" y, como ese camino es un no camino, tendríamos que seguir a Parménides en su ecuación entre Ser y Pensar, lo que nos dejaría chapoteando en el pantano extendido entre la tautología y el silencio, como al Wittgenstein del Tractatus... (Y si quisiéramos salirnos con la nuestra a pesar de todo o, mejor dicho, con el Todo, todos seríamos eternamente Hegel).

Somos invitados entonces a un juego aristotélico: el lenguaje se dice de muchas maneras. Como facultad puede ser estudiado y, en el mejor de los casos, explicado, en términos de la filogénesis y la ontogénesis, en sentido amplio, esto es, reuniendo los esfuerzos de la antropología, la biología, la historia, la lingüística, la psicología y la sociología en una teoría unificada o, más plausiblemente, en una ciencia básica en la que se formulen las leyes correspondientes a las que todo ese amasijo de conocimientos se reduciría.

Otra de las maneras en las que se dice el lenguaje es en términos de la pluralidad de las lenguas existentes - alrededor de 6000 según algunos lingüistas -. Es un terreno más manejable en el que el trabajo interdisciplinario, por ejemplo, entre la etnolingüística y la neurología, promete mucho.

Sin embargo, el avance en el conocimiento científico del lenguaje como facultad y en el de las lenguas como sus diversas manifestaciones, nos daría una teoría del lenguaje en la que los problemas de la filosofía que se agitan dentro 
de esa búsqueda del absoluto a la que hicimos referencia, no tendrían respuesta, pues ni siquiera podrían ser formulados.

Podríamos sencillamente desestimar por mítica esa dimensión soñada, como dejamos atrás, al parecer, las explicaciones teológicas según las cuales el lenguaje es un don con el que Dios distinguió al ser humano por encima de todo el resto de su creación. Pero ese gesto de autosuficiencia sería tirar al bebé con el agua sucia.

Por otra parte, el campo de lo que seguiremos llamando filosofía del lengua$j e$, no fusiona todos sus problemas típicos en esa única búsqueda del lenguaje como absoluto: también en la filosofía, el lenguaje se dice de muchas maneras. A continuación, veremos algunas de las principales imágenes o figuraciones que el lenguaje ha adoptado en la filosofía contemporánea, ponderando de qué modo el enfoque filosófico logra su mayor pertinencia, no cuando compite con las teorías científicas, de las que puede beneficiarse, sino cuando expresa, en una representación integral, al lenguaje como articulación práctica de la existencia.

El modo en que los grandes filósofos de la Grecia antigua se interrogaron por el lenguaje nos sitúa en la proximidad del hambre de absoluto que respecto de él tienta al filósofo. Una expresión culminante de ello es el diálogo El Sofista de Platón, en donde se inquiere, con profunda perplejidad, acerca de cómo es posible decir lo que no es. Se admite el no ser a través de un "giro lingüístico", por así decir, pues se lo introduce a fin de explicar el discurso falso. Por este camino, Platón, en su afán de derrotar al sofista, condena a la filosofía a divorciarse del absoluto.

Esta posibilidad, la de decir lo falso, sería, en la concepción platónica, connatural al lenguaje, tanto como su capacidad de ser verídico, - sin embargo, sólo aquella parece configurar el problema filosófico allí, como si el discurso verdadero fuera de suyo-. Aquí Platón se vuelve el parricida de Parménides, al condescender con la tesis de que el no ser también pertenece al lenguaje y al pensamiento. Más aún, por albergar la falsedad en el discurso, este queda marcado en su ser, pues será de la índole del logos la bipolaridad proposicional, por ende, su capacidad de ser verídico -

Haber recordado la doctrina platónica del lenguaje y el no ser es un buen preámbulo para acercarnos a la concepción benjaminiana. Dar cuenta de esta compleja y extraordinaria perspectiva de forma esquemática no es satisfactorio, 
pero en este contexto será inevitable. Para introducirnos de golpe y rápidamente en ella comenzamos por señalar que Benjamin, si bien reivindica la teoría de las ideas de Platón, en lo que concierne al lenguaje su referencia fundamental es la tradición bíblica. Veámoslo más de cerca.

La representación benjaminiana pretende dar cuenta de tres planos del lenguaje: el de la facultad, el de su ser en tanto lenguaje humano en relación al sentido en general y, por último, el de la pluralidad de las lenguas y la posibilidad y función de la traducción. Benjamin adopta el relato bíblico en la siguiente interpretación:

(Resumo en mis propios términos) Dios crea todas las cosas al nombrarlas, menos al hombre, al que hace con barro y le insufla el aliento, tal que él pueda nombrar todas las cosas a su vez, siendo esta su facultad exclusiva, convergente con - por momentos pareciera incluso dependiente de - el hecho de no haber sido creado por un nombre de Dios. En segundo lugar, debido a que todas las cosas han recibido un nombre de Dios y la capacidad nominativa del humano deviene del artificio de Dios, con lo que se le supone una participación en lo divino, el lenguaje adánico, que sería la vida secreta de todo lenguaje, puede comunicar su espiritualidad y la de todas las cosas. Es decir, el ser lingüístico que somos presta su voz a un mundo pleno de sentido, pero mudo, voz que resuena en los nombres de las cosas, o se vislumbra en la representación de sus ideas, vistas estas bajo el modelo platónico. Finalmente, cada lengua es una expresión parcial, incompleta del lenguaje adánico, por lo que la traducción es el lugar de, en cierta forma, su restitución en el mundo de los pecadores. A pesar de ello, debido a que el lenguaje humano introduce el juicio, a quien compete la polaridad bienmal (o verdadero-falso podríamos agregar) y la capacidad de la referencia a lo abstracto, la recuperación de un lenguaje puramente nominativo como el adánico, próximo al lenguaje de la creación, nos resulta inaccesible.

Despojada de su sugestivo ropaje alegórico, esta idea de lenguaje puede ser asociada a tesis destacables: 1) el lenguaje no puede fundarse a sí mismo, siempre hay un lenguaje dado del que se parte: la lengua materna, por caso, o paterna, en la alegoría benjaminiana, respecto de la cual no hay fundamento racional - hasta ahora tampoco hay explicación empírica, agreguemos - ; 2) la alegoría de Benjamin aleja una imagen envolvente, causada por una 
comprensión equivocada del giro lingüístico, al sugerir que no estamos hechos de palabras; 3) el vínculo entre las palabras y las cosas no es meramente convencional. (Por otra parte, si lo fuera, las cosas igualmente no serían escindibles de las propiedades o significados que las palabras le han transferido); 4) la traducción acrecienta el ámbito de la significación auténtica, de las cosas mudas al lenguaje humano que le da su voz y de cada lengua potencialmente a todas las demás, camino por el cual la experiencia y el lenguaje limitado de una lengua en particular se redimen a través de su renacimiento en la matriz de las otras lenguas. Por el camino de la traducción, la supuesta inefabilidad de lo que cada lengua muestra, pero no es capaz de decir, es tangencialmente comunicable en su despliegue hermenéutico.

En esta perspectiva, nuestra experiencia del mundo es relativa a la lengua con la que hacemos esa experiencia, pero esto no vuelve a las cosas nóumenos inalcanzables ni transforma a cada lengua en una especie de cárcel que nos condena a hablar de palabras según un esquema autista.

Esos planteos, como los del convencionalismo, son producto de una división o dicotomía entre las palabras y las cosas que resulta arbitraria. Quizá inducidos por la modernidad, - en la que fue posible, por ejemplo, que un Kant dijera que el escándalo de la filosofía radica en no poder dar cuenta de cómo algo en la mente representa algo fuera de la mente -, partimos de la separación entre las palabras y las cosas para luego buscar reunirlas, lo que parece condenado al fracaso.

Pero nuestro mundo de cosas encarna propiedades que no tendría sin nuestras palabras, al punto que, como puede apreciarse con ayuda de estudios lingüísticos, ya al nivel del sector en donde más próximo nos encontramos de lo que pudiera considerarse independiente de nosotros, nuestras representaciones varían en función de idiosincrasias lingüísticas: la representación espacial de los objetos, su distribución en géneros y la clasificación de sus colores, por ejemplo. Es que hay una normatividad del lenguaje, de cada lengua, respecto de la cual no somos libres.

Por otra parte, y mal que le pese a Benjamin, los nombres y las cosas viven su vida común en el seno del discurso en donde reina, para reponer sus términos, "la palabra juzgadora", es decir, aquello que liga el sentido a la norma veritativa. Pero esto sería de lamentar sólo si siguiéramos siendo preplatónicos, en contra de lo que el filósofo ateniense desarrollara en su Sofista. (Tal vez Benjamin piense 
especialmente en el lenguaje poético, en el que puede reinar el nombre/cosa sin discurso. Por otra parte, hay que recordar que en su concepto la verdad es del ser, no de la proposición, o, dicho de otra manera, en su visión alegórica, la verdad no es objeto de conocimiento, sino que se percibe al nombrar las ideas que conectan los fenómenos entre sí, pero no nos interesa ahora indagar en estas peculiaridades de su representación del lenguaje).

Benjamin no pretendió que su filosofía del lenguaje tuviera algún poder explicativo, algo que sólo es dable esperar de las teorías científicas del lenguaje, pues en ese caso se procura incrementar nuestro conocimiento, algo que la filosofía no podría proporcionarnos en la visión del filósofo berlinés. Su importancia debe evaluarse bajo la luz de lo que pretendía con ella, a saber: dar una representación o constelación de ideas en las que el lenguaje tomara su papel junto a muchas otras, todas ellas relativas a una comprensión práctica y existencial de la condición humana.

(Cabe señalar, incidentalmente, que lo mismo corresponde decir, sin embargo, de un libro tan diferente de los textos de Benjamin como lo es el Tractatus... de Wittgenstein, aun desde la propia concepción de la filosofía del filósofo vienés. Como se recordará, según se afirma en esa obra, la filosofía no aporta nuevo conocimiento acerca de hechos sino más bien una clarificación del marco dentro del cual se dan sus descripciones. Es lo que luego llamará representación perspicua, cuyo sentido último es práctico y existencial, no teórico y cognoscitivo. (La palabra alemana que traducimos por representación es en ambos casos, en Benjamin y en Wittgenstein, la misma: darstellung). Comparando ambas representaciones, las analogías son notables, sin por ello obviar las también notables diferencias. En particular, ambas imágenes aluden a un lenguaje fundamental en el que el señorío corresponde al nombre y con el que el lenguaje natural guarda un vínculo esencial. En el T. esos nombres originarios no son los de Adán, ciertamente, sino los inscriptos eternamente en la forma lógica, pero como ha dicho Isidoro Reguera, la forma lógica es el Dios del T.).

Volviendo a nuestras "tesis benjaminianas", me interesa enfatizar la dimensión comunitaria implicada en su concepción de la traducción. Si bien pareciera haber un criterio trascendente de corrección, proporcionado por el hecho de que el referente último es el nombre originario, parcialmente comprendido en los diferentes nombres de las distintas lenguas, este criterio no es directamente operativo, ya que no poseemos ni podemos poseer ese lenguaje, sino que permanece como un ideal inspirador para realizar lo que verdaderamente importa: el 
lenguaje de la traducción en el cual nos es dada la comunicación del mundo en el lenguaje verbal y de cada lengua en todas las demás en las que nos logramos instalar.

Una breve comparación con ideas similares de otro filósofo judío alemán de la misma época y del mismo ambiente cultural, nos ayudará a clarificar la idea. Me refiero a Franz Rosenzweig, de quien cito:

No hay nada a lo que la palabra no siga de cerca. El lenguaje es apéndice del mundo. No es el mundo, ni pretende serlo. ¿¿Pero qué es entonces? [...] ¿Qué lugar queda entonces todavía para el lenguaje? [...] Sólo le cabe una cosa: tender un puente entre el mundo y lo demás. Y eso es lo que hace. [...] La palabra no es una parte del mundo. Es el sello del hombre (1994, pp. 54 y 55$)$.

Como en Benjamin, esta palabra del hombre no es pura convención, ni arbitraria ni relativa. Y si no lo es, es en virtud de la confianza con la que se la renueva, se la traslada y traduce, más allá de su comienzo, pero conservando su fuerza originaria hasta alcanzar la palabra final, que coincidirá con la palabra de Dios. (Nuevamente, esto puede sonar extraño si se lo contempla a través de la asepsia habitual del abordaje lógico-analítico del lenguaje, pero no está muy lejos de un gran "racionalista", en sentido amplio, como Peirce, si se recuerda su peculiar pragmatismo semiótico sobre el conocimiento y la verdad).

Mundo, hombre y Dios, las tres dimensiones de la existencia en la perspectiva de Rosenzweig, armonizan en estos términos por obra y gracia del lenguaje:

Hasta en la más pequeña de las cosas actúan así, unas sobre otras, las tres potencias. Hay un trozo de mundo; unos hombres le dan su nombre; Dios le pronuncia, a esa cosa múltiplemente nombrada, la sentencia de su destino. [...] Pues el mundo sólo es realmente en este acontecer que comprende cada punto de su ser en el intervalo entre palabra humana y sentencia divina. No hay un mundo en sí. Hablar del mundo quiere decir: hablar del mundo que es nuestro y de Dios (Idem, p. 59).

En las imágenes de Benjamin y de Rosenzweig, como vemos, el lenguaje se presenta con una duplicidad: como lenguaje del mundo, entendido este 
como creatura, y como lenguaje del hombre. Pero esta doble vida del lenguaje se sostiene dentro de una concepción deísta. Si prescindimos del deísmo, ¿se cancela dicha duplicidad? ¿Cuáles son las consecuencias más vastas cuando la presencia de Dios abandona nuestras palabras?

Estas figuras alegóricas del lenguaje encuentran en Dios su fundamento. Pero en ausencia de Dios, ¿conservaría aún nuestro lenguaje algo así como un fundamento? Ocurre que en la idea de fundamento se integran muy diversas cosas: explicación, origen, causa, norma, ser...; nada como Dios para reunir en una sola instancia todo eso. Por ello, en su ausencia, las preguntas se separan, abriendo diversos campos de investigación sobre el lenguaje.

De todos esos caminos nos interesa indagar por el ser del lenguaje para, a partir de ello, esclarecer el modo en que éste se constituye en una instancia estructural de la existencia. Si bien exposiciones como las de Benjamin y Rosenzweig parecen apuntar a lo mismo, la dimensión deísta sólo podría admitirse como símbolo expresivo, de ningún modo como descripción o análisis, que es el modo con el que estamos comprometidos.

Tienen razón esos autores en ubicar al lenguaje como una dimensión social, comunitaria de la existencia, forjada a través de la comunicabilidad plena potencialmente infinita - del mundo en el lenguaje, de cada lengua en todas las demás.

Es la redención de Babel con Pentecostés, como ha señalado Murena: al confundir las lenguas, nos dice el ensayista argentino, Yahveh libera al hombre, irónicamente, de la locura del discurso único, de la obsesión del regreso: le indica que el camino de retorno está para él sólo a través de la aceptación de la diversidad. Pero, completa, el símbolo de Babel ha de leerse junto al de Pentecostés:

Pentecostés es paralelo a Babel, pero es, sobre todo, lo contrario. [...] En Pentecostés late de manera singular el afán de comunicar. ¿Comunicar qué? La Unidad. Como en el reino de la diversidad esto es absolutamente imposible, se desfigura el orden natural del mundo, se hace que unas criaturas hablen en lenguas que hasta ese instante ignoraban.

Estas criaturas se hallan inspiradas de manera especial. Así logran anular de manera repentina la distancia y, con su fervor en el Otro Mundo, consiguen traerlo a éste, que se ve por ello transfigurado (2002, p. 458). 
Pero, nuevamente, el símbolo, la imagen, la metáfora permiten el fulgor intuitivo del rayo. Es necesario irradiar esa luz a través de su difusión analítica y descriptiva. A tales fines, nuestro punto de partida es el reconocimiento pleno de que el ser del lenguaje es la base material que estructura nuestra existencia, nuestro "ser en el mundo". Para dar cuenta del mismo, han de integrarse en una reconstrucción unitaria el punto de vista del hablante, tanto en el contexto ontogenético en el que un no hablante se transforma en hablante, como en el contexto normalizado en el que la conciencia adquiere su consistencia como ser social en la comunicación, es decir, en la vida dinámica de los signos en su realidad semiótica.

Adoptar este punto de partida es aceptar, en vena wittgensteiniana, que quien está en el lenguaje está en las cosas mismas y, viceversa, que nadie está en las cosas mismas sin estar en el lenguaje. Estar en las cosas mismas es estar en la forma de vida y estar en el lenguaje es haber aceptado tomar la palabra como respuesta a la invocación recibida de parte de la comunidad de habla en la que se ha nacido, integrándose a ella como un hablante más.

Palabra y cosa son anverso y reverso de una sola y única realidad, por lo que cualquier tesis filosófica que implique la imagen de una unidad formal llamada "lenguaje" como una especie de red arrojada sobre lo real para pescar cosas, es el alimento de mitologías conceptuales variopintas. De igual manera que pretender dar cuenta de una realidad estructurada más allá del lenguaje, pero emparejada con él como su reflejo en un espejo -a cada proposición verdadera el hecho que la hace tal; a cada cosa su exclusivo y esencial nombre-.

La falsa alternativa a la que nos enfrenta esa mirada abstracta sobre el lenguaje es la siguiente: o bien hay una separación radical entre las palabras y las cosas, -y entonces algo más básico que el lenguaje y el mundo comunes debe unirlas-, o bien hay una unidad esencial, más allá de tal aparente separación -pero ya no concebible como lenguaje y mundo comunes-. Quien acepte esta alternativa, será llevado a preguntar dónde y cómo está dada o se alcanza esa unidad, sin que el trabajo de la filosofía deba nada al lenguaje ya enraizado en el mundo con el que se articula, ni a éste, en tanto instancia articulada con aquél.

Sostenida por el presupuesto de esta alternativa, la filosofía se transforma en una vía de desarraigo de toda forma de vida, adoptando una perspectiva abstracta sobre los vínculos entre lenguaje y la realidad. Una vez emprendida esa marcha, la incomprensión de nuestra condición como hablantes de un lenguaje 
es inevitable, generando la perplejidad filosófica y la subsecuente necesidad de teorías que la disipen.

La alternativa en cuestión es aparente, pues entre las palabras y las cosas no hay lugar alguno en el que habitar. (Diferente es concebir un más allá de la unidad palabra-cosa como el fondo inaccesible de lo sensible, terreno movedizo en el que sería impropio ubicar lo discreto y estructurado, rasgos tanto de los nombres y las proposiciones, como de la referencia y las situaciones que hacen verdadera o falsa a éstas - por limitarnos sólo a la función asertiva del lenguaje-).

En consecuencia, sólo queda en pie una de las dos opciones: la que concibe una unidad originaria de naturaleza peculiar, separada del lenguaje común, pero también del mundo común. ¿En qué podría consistir esta rara unidad? El mejor candidato, si no el único, es precisamente, el mundo de lo privado, uno de cuyos lados se pretendería aun lenguaje, mientras el otro estaría habitado por su correlato inmediato, sea esto lo que fuere.

Para comprender cómo se llega a este postulado, podemos valernos del problema russelliano que originara su teoría de las descripciones. Recuérdese el célebre ejemplo: "El actual rey de Francia es calvo". El análisis de Russell trató la expresión "el actual rey de Francia" como un nombre aparente, cuya función en la oración no era realmente ser su sujeto lógico. En este ejemplo, lo que hace de esa expresión un nombre aparente no es, naturalmente, el hecho de que Francia no sea ya una monarquía, sino que sea una descripción. Cualquier descripción, aun una de cuyo objeto se pueda afirmar con verdad que existe -y lo que la descripción le atribuye-, tampoco sería un nombre.

Para Russell, un auténtico nombre no puede en ningún caso carecer de denotación, constituyéndose ésta en su única significación. Para garantizarlo, se requieren pronombres que funcionen como nombres propios. A su vez, las significaciones o denotados de estas expresiones tienen que ser forzosamente algo de lo que se tenga experiencia inmediata, respecto de la cual no quepa error de juicio alguno.

La consecuencia anómala de este resultado es que las proposiciones obtenidas a través de este análisis, a pesar de no ser tautologías ni verdades necesarias bajo ningún concepto, nunca pueden ser falsas. Para ellas, tener sentido y ser verdaderas son lo mismo. 
En cambio, las proposiciones que no contienen nombres genuinos retienen la bipolaridad verdadero-falso, pero al precio de perder el vínculo denotativo entre el lenguaje y su referencia. Pagado este precio, las proposiciones que no contienen nombres genuinos pueden ser significativas $y$, como tales, verdaderas o falsas. Así resulta porque su forma lógica contiene afirmaciones existenciales y, como tales, generales. Por contraste, las proposiciones cuyo sujeto lógico es un pronombre en función nominativa, no contienen generalidad, denotan lo simple.

En la concepción russelliana, el modelo objeto-designación, como lo llamaremos con Wittgenstein, puede generalizarse a todo el lenguaje, pues las proposiciones que contienen generalidad constituyen lo que Russell llamó conocimiento por descripción, pero todo el contenido de este conocimiento, para ser tal, debe poder remitirse en última instancia a lo que llamó conocimiento directo, precisamente el que se expresa en las proposiciones que contienen sólo nombres genuinos.

Ahora bien, es claro que accede al conocimiento directo sólo aquel que experimenta directamente los estados de cosas por él descriptos. Pero el lenguaje que expresa esta experiencia y conocimiento directos agota su significado en los denotados así experimentados. ¿Cómo puede ahora concebirse este lenguaje como común a distintos sujetos de distintas experiencias? Que la experiencia no puede ser común se sigue de que, si lo fuera, podría ser objeto de un conocimiento por descripción, o bien permanecer cierta exclusivamente en el propio caso, pues ¿Cómo podría alguien estar cierto de que lo que experimenta el otro es lo mismo que experimenta él mismo?

Si hemos presentado sumariamente la concepción russelliana del modelo objeto-designación, es porque constituye un paradigma filosófico poderoso que induce a una concepción mitológica que desnaturaliza el ser social del lenguaje, al exigir como complemento de su noción de significado, una determinada imagen del pensamiento, esto es, la de un proceso interno, oculto, que acompańa como una sombra al lenguaje en su alcance semántico.

Para superar la atmósfera mitológica en la que queda envuelta la comprensión del lenguaje en esta y otras representaciones similares, es necesario reponer los contextos dinámicos en los que el hablante/viviente articula su existencia a través del lenguaje en su dimensión práctica, sea el ontogenético en el que el aún viviente no hablante se vuelve hablante, sea en los más diversos contextos 
en los que, lo que es una vivencia propia y singular desde el punto de vista de la conciencia individual, alcanza su realidad social de signo.

En el modelo privado objeto-designación, ¿podríamos acaso tener un nombre común para referirnos a un tipo de ese algo que queremos mencionar? ¿Podríamos incluso tener nombres propios?

En ambos casos lo único que tendríamos, como muestra Wittgenstein en If 258-261, es un sonido asociado a una experiencia a través de una especie de ostensión privada, pero este sonido, de no estar vinculado normativamente con esa experiencia, volvería a ser tan sólo un sonido inarticulado, que era lo que por caso tenía el niño antes de adquirir el lenguaje natural a partir del enseñamiento del adulto.

Lo que queríamos era pasar del sonido inarticulado al lenguaje y, por este camino, no nos hemos movido aun un paso. La clave está en la exigencia de normatividad, una regla respecto de la cual quepa la distinción correcto/incorrecto cuando se la aplica. Ahora debiera concebirse una regla en términos puramente privados, ¿puede concebirse una regla así? Si lo que oficia de regla es nuevamente la asociación de un signo arbitrario -o un grito inarticulado- con una experiencia, el caso se homologa al anterior, por lo que la fundamentación buscada no habría procedido, es decir, careceríamos aún de la fuerza normativa requerida.

Cabe no obstante señalar, que no se trata de acusar de mitológica solamente a la visión del lenguaje que nos proporcionan los partidarios del lenguaje privado, sino también y por lo mismo al platonista del sentido, al realista de la mente o del significado, al naturalista científico, sea en la variante natural o social, al fenomenólogo trascendentalista y a todo aquél que pretenda suprimir la tensión y el movimiento dialéctico que se establece en nosotros entre las palabras, el sentido y la experiencia. La moraleja es que no hay atajos para la filosofía, condenada a enfrentar el arduo trabajo de la crítica de sí misma y de las condiciones subjetivas y objetivas de su realización en cada situación.

La filosofía del último Wittgenstein es un poderoso antídoto crítico para curarnos de todas esas mitologías filosóficas. Sin embargo, su antimentalismo le jugó una mala pasada, porque le impidió lograr restituir adecuadamente la perspectiva de la comprensión, al no proporcionarnos una imagen en la que la vivencia consciente se integre por derecho propio al vínculo semiótico. 
A fin de avanzar en ese sentido, sumaremos sucintamente dos referencias contemporáneas más en nuestro camino de completar una figura del lenguaje que nos permita recuperar lo que puede ser conservado de aquella búsqueda de absoluto con la que comenzamos.

Prometedora en esa orientación crítica, es la filosofía del lenguaje elaborada por Volóshinov y por Bajtín. Dar cuenta cabal de la misma implicaría recorrer y sistematizar muchos textos, lo que estaría fuera de lugar en el presente trabajo. Nos contentaremos con unas pocas citas de El marxismo y la filosofía del lenguaje, cuya autoría se le atribuye al primero de los nombrados.

Para apreciar la fuerza y el alcance de las citas que seguirán, necesito explicitar la orientación general del libro. En dicha obra se afirma que la filosofía del lenguaje es la herramienta básica para el estudio crítico de las ideologías, pues el lenguaje como tal es concebido como una estructura ideológica, aunque neutral en relación a ideologías más específicas que lo presuponen.

El estudio del lenguaje, según Volóshinov, debe dar a quien lo suyo: a las perspectivas del hablante y del intérprete la soberanía relativa de la realidad dinámica que articula la vivencia individual en el medio de la comunicación social, y a la estructura de la lengua la normatividad inmanente a su historia y a la dinámica de la comunicación, que sólo metodológicamente puede aislarse para considerarla como una estructura o sistema formal de señales que presionan normativamente sobre la comunicación. Teniendo presente esta contextualización leamos los siguientes pasajes:

Sin contar con una objetivación, con una expresión mediante un material determinado (el material del gesto, de la palabra interna, del grito), la conciencia es una ficción. [...] Pero la conciencia en cuanto expresión material organizada (mediante el material ideológico de la palabra, del sonido, del signo, del dibujo, del color, de la música), es un hecho objetivo y una enorme fuerza social. Es verdad que la conciencia no se encuentra por encima de la existencia ni la puede determinar constitutivamente, pero en cambio es una parte de la existencia, una de sus fuerzas y por lo mismo posee una eficacia, juega un papel en la arena de la existencia (2009, p. 144).

Y más adelante: 
El mundillo de una vivencia puede ser muy estrecho y oscuro, la orientación social de la vivencia puede ser eventual e instantánea...Una semejante vivencia fortuita permanece aislada en la vida psíquica de una persona determinada. No es capaz de consolidarse y encontrar una expresión diferenciada y acabada... Tales vivencias constituyen el estrato inferior, inestable y sumamente cambiante de la ideología cotidiana. [...] Los estratos superiores de la ideología cotidiana, que son contiguos a sistemas ideológicos, resultan más consistentes, responsables y de índole creativa. [...] Lo que suele llamarse "individualidad creativa" representa la expresión de una línea firme y permanente en la orientación social de una persona [...] (pP. 147-8).

\section{Finalmente:}

El centro organizador de cada enunciado, de cada expresión no se encuentra adentro sino afuera: en el medio social que rodea al individuo. Sólo un grito animal inarticulado aparece organizado, en efecto, desde el interior del aparato fisiológico de un individuo aislado. Este grito no agrega ningún matiz ideológico a la reacción fisiológica. Pero incluso el enunciado más primitivo de un hombre, realizado por un organismo singular, se organiza fuera de este, en las condiciones extraorgánicas del medio social (p. 149).

En resumen, para Volóshinov el lenguaje no es una estructura normativa abstracta desvinculada de la faz intersubjetiva en la que se manifiesta, pero tampoco es engendrada en la intimidad de sujetos constituidos como tales fuera del lenguaje. Por el contrario, el desafío para una filosofía del lenguaje consiste en dar cuenta de la comprensión como centro generador del signo en tanto vínculo social entre conciencias.

Por otra parte, a mayor inserción de la espontaneidad subjetiva en la significación social, -ideológica en los términos del autor-, mayor creatividad y libertad en relación a las fuerzas alienantes de los dispositivos ideológicos. Es decir que la pertinencia de la conciencia, eliminada en la estrategia descriptiva wittgensteiniana, radica en ser la instancia dinámica en la que la realidad de la lengua como forma normativa, alcanza su concreción y su capacidad de renovar la expresión de la vida colectiva, tanto en su articulación con el organismo como con el mundo material que lo circunda. 
No se trata de afirmar ninguna autonomía de la conciencia en relación al lenguaje, ya que, por fuera de la materialidad del signo, aquella se desintegraría, subsistiendo solamente el proceso vital del organismo. Para éste, volverse signo y expresarse en la conciencia son una y la misma cosa. Más allá o más acá de esa expresión, nos reencontraríamos con la vida sin lenguaje, como en el animal o en el niño no socializado, con ambiente más que mundo, como se ha dicho desde hace tiempo y, por otro lado, con una estructura abstracta fantasmagórica, a la que sólo imaginariamente podría representársela como un lenguaje. (En este punto, deberíamos discutir con el posestructuralismo, pero no hay posibilidades de hacerlo aquí y ahora).

Observemos que, paradójicamente, por este camino crítico en el que aceptamos perder el absoluto al que aludíamos al comienzo, y del que también apartamos toda divinidad, en cualquiera de sus posibles metamorfosis, hemos conseguido finalmente una representación del lenguaje que conserva algo del absoluto sońado o perdido. En efecto, y para terminar con una última referencia, afirmaremos con Sartre que el lenguaje...

[...] no puede ser separado del mundo, de los otros y de nosotros mismos: no es un enclave extrańo que me puede cercar o desviarme de mi propósito; soy yo, en tanto que estoy más cerca de ser yo mismo cuanto más lejos estoy, con los otros, y entre las cosas. Es la indisoluble reciprocidad de los hombres y sus luchas, puestas de manifiesto, conjuntamente, por las relaciones de ese todo lingüístico sin puertas ni ventanas, en el que no podemos entrar, del que no podemos salir y en el que estamos [...] nada precede al lenguaje...hemos pasado sin esfuerzo, merced a nuestra simple afirmación práctica de nosotros mismos, del alma hablada al alma hablante (1975, pp. 23, 24 y 51). 


\section{Referencias bibliográficas}

Benjamin, W. (2007). "Sobre el lenguaje en general y sobre el lenguaje de los hombres", reproducido en Walter Benjamin, Conceptos de filosofia de la historia, Caronte, Buenos Aires, pp. 91 a 108.

Murena, H.A. (2002). La metáfora y lo sagrado, reproducido en Héctor A. Murena, Visiones de Babel, F.C.E., Buenos Aires.

Rosenzweig, F. (1994). El libro del sentido común sano y enfermo, Caparrós Editores, Madrid.

Russell, B. (2013). "Sobre la denotación", reproducido en Bertrand Russell, Lógica y conocimiento, RBA, Barcelona, pp. 69 a 94.

Sartre, J.-P. (1975). El idiota de la familia, Editorial Tiempo Contemporáneo, Buenos Aires.

Volóshinov, V. N. (2009). El marxismo y la filosofía del lenguaje, Ediciones Godot, Buenos Aires.

Wittgenstein, L. (1973). Tractatus lógico-philosophicus, Alianza, Madrid.

- (1999). Investigaciones filosóficas, Altaya, Barcelona.

Recibido: 16/03/2016

Aceptado: 12/09/2016

Este trabajo se encuentra bajo una licencia de Creative Commons Reconocimiento-NoComercial-SinObraDerivada 4.0 Internacional 
